\title{
BMJ Open Suicide in Canadian veterans living in Ontario: a retrospective cohort study linking routinely collected data
}

\author{
Alyson L Mahar, ${ }^{1}$ Alice B Aiken, ${ }^{2}$ Marlo Whitehead, ${ }^{3}$ Homer Tien, ${ }^{4}$ Heidi Cramm, ${ }^{5}$ \\ Nicola T Fear, ${ }^{6}$ Paul Kurdyak ${ }^{7}$
}

To cite: Mahar AL, Aiken AB, Whitehead M, et al. Suicide in Canadian veterans living in Ontario: a retrospective cohort study linking routinely collected data. BMJ Open 2019;9:e027343. doi:10.1136/ bmjopen-2018-027343

- Prepublication history and additional material for this paper are available online. To view please visit the journal (http:// dx.doi.org/10.1136/bmjopen2018-027343).

Received 17 0ctober 2018 Revised 22 April 2019 Accepted 7 May 2019

\section{Check for updates}

(C) Author(s) (or their employer(s)) 2019. Re-use permitted under CC BY-NC. No commercial re-use. See rights and permissions. Published by BMJ.

${ }^{1}$ Community Health Sciences, University of Manitoba College of Medicine, Winnipeg, Manitoba, Canada

${ }^{2}$ Office of Research and Innovation, Dalhousie University, Halifax, Nova Scotia, Canada ${ }^{3}$ ICES, Toronto, Ontario, Canada ${ }^{4} 1$ Canadian Field Hospital, Canadian Armed Forces, Toronto Ontario, Canada

${ }^{5}$ School of Rehabilitation Therapy, Queens University, Kingston, Ontario, Canada ${ }^{6}$ ADMMH, King's College London, London, UK ${ }^{7}$ Institute for Mental Health Policy Research, Centre for Addiction and Mental Health Toronto, Ontario, Canada

Correspondence to Dr Alyson L Mahar; alyson_mahar@cpe.umanitoba. ca

\section{ABSTRACT}

Objectives To compare the risk of death by suicide in male veterans with age-matched civilians.

Design Retrospective cohort study linking provincial administrative databases between 1990 and 2013 with follow-up complete until death or December 31, 2015. Setting Population-based study in Ontario, Canada. Participants Ex-serving Canadian Armed Forces and Royal Canadian Mounted Police veterans living in Ontario who registered for provincial health insurance were included. A civilian comparator group was matched 4:1 on age and sex.

Main outcome Death by suicide was classified using standard cause of death diagnosis codes from a provincial registry of mandatory data collected from death certificates. Fine and Gray sub-distribution hazards regression compared the risk of death by suicide between veterans and civilians. Analyses were adjusted for age, residential region, income, rurality and major physical comorbidities.

Results 20397 male veterans released to Ontario between 1990 and 2013 and 81559 age-sex matched civilians were included. $4.2 \%$ of veterans died during the study time frame, compared with $6.5 \%$ of the civilian cohort. Death by suicide was rare in both cohorts, accounting for $4.6 \%$ and $3.6 \%$ of veteran and civilian deaths, respectively. After adjustment for confounders, veterans had an $18 \%$ lower risk of dying from causes other than suicide ( $\mathrm{HR} 0.82,95 \% \mathrm{Cl} 0.76$ to 0.89 ) and a similar risk of dying by suicide (HR $1.01,95 \% \mathrm{Cl} 0.71$ to 1.43), compared with civilians.

Conclusions Deaths by suicide were rare in male veterans residing in Ontario. Our findings demonstrate that veterans had a similar risk of suicide-related mortality as an age-matched civilian population. A better understanding of effective suicide prevention as well as clarifying pathways to seeking and receiving mental health supports and services are important areas for future consideration.

\section{INTRODUCTION}

A constellation of factors may increase the likelihood of death by suicide in military veterans. Established population-based risk factors, including being male, having a personal history of childhood abuse, a personal history of trauma and/or mental disorders, experiencing current financial

\section{Strengths and limitations of this study}

- Population-based design cohort study linking universal health system data with national mortality data ensures excellent follow-up coverage and similar capture of deaths by suicide between veterans and civilians.

- Despite both matching and inclusion of key variables associated with suicide risk that were not on a causal pathway to death by suicide (eg, socioeconomic status and physical comorbidity), residual confounding is still possible.

- This first study of suicide risk in Canadian veterans did not have details on potential explanatory factors of suicide risk specific to military service, which would be important to understanding heterogeneity in risk within the veteran population.

- The absolute risk of suicide and the presented associations may not be generalisable to other countries with different military culture, length of service, deployment and combat experience; direct comparison may not be appropriate.

hardship or the breakdown of intimate relationships, are relevant to the ex-serving population. ${ }^{1}$ Military-specific risk factors, such as operational conditions of training and deployment including sleep deprivation, stress and exposure to traumatic events ${ }^{1-6}$ may interact with these established factors and continue to exert an effect long after initial exposure, further increasing the risk of suicide over time. ${ }^{7}$

Despite the large amount of attention on the issue of suicide among military populations, the literature is sparse and inconsistent. ${ }^{8-13}$ Findings vary depending on country of origin, service period of reference and the definition of veteran status. There are even fewer Canadian studies of veteran populations. ${ }^{14}$ A recent governmental report from Veterans Affairs Canada (VAC) used national vital statistics data linked to administrative Department of National Defence (DND) records concluded a higher risk of suicide 


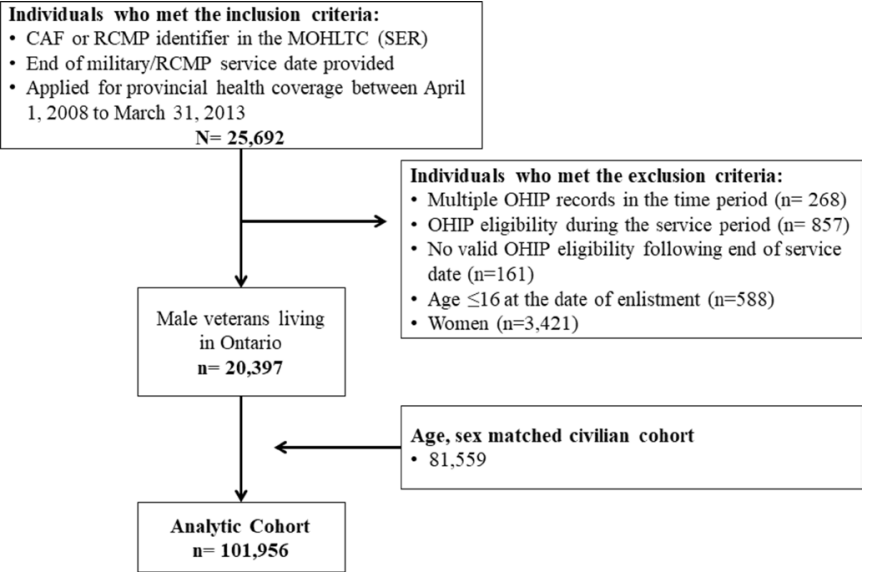

Figure 1 Selection of study cohort. CAF, Canadian Armed Forces; MOHLTC, Ministry of Health and Long-Term Care; OHIP, Ontario Health Insurance Plan; RCMP, Royal Canadian Mounted Police; SER, It is the three letter code that indicates the eligible insuree is a Canadian Armed Forces or RCMP veteran.

for young male veterans, and female veterans, relative to the general population. ${ }^{15}$ The VAC study and many others internationally studies are limited by their inability to make direct comparisons with a similar civilian cohort or to adjust for established risk factors and potential confounders such as socioeconomic status or rurality.

The primary aim of this paper was to describe and compare the rates of death by suicide in Canadian male veterans living in Ontario with age and sex matched civilians, adjusting for key confounders.

\section{METHODS}

\section{Study design}

This was a retrospective, cohort study using provincial, routinely collected data and set in Ontario. ${ }^{16-19}$ Ontario is home to 8 of the 38 Canadian federal military bases, including the major operational bases Canadian Forces Base Kingston and Petawawa, the Royal Military College of Canada, the DND Headquarters and national headquarters for the Royal Canadian Mounted Police (RCMP). In Ontario, universal healthcare planning and delivery is separated into 14 distinct geographic regions. With 13.7 million inhabitants, Ontario is also the most populous province in Canada, making it an ideal province to study rare outcomes such as death by suicide. The authors followed the STROBE reporting guidelines. ${ }^{20}$

\section{Patient and public involvement}

Patients and/or the public were not involved in the design or analysis of this study.

\section{Study population}

Veterans were defined as previous Canadian Armed Forces (CAF) and RCMP members who provided evidence to the Ontario Ministry of Health and Long-Term Care (MOHLTC) of their career history, typically at the time of Ontario Health Insurance Plan (OHIP) provincial healthcare registration. The MOHLTC provided an anonymised list of people with an administrative CAF and RCMP service code linked to their health card number to Institute for Clinical Evaluative Sciences (ICES), as well as career start and end dates. At the time of service departure, health insurance coverage is switched from federal to provincial oversight and waiting periods for provincial health insurance are waived, which has resulted in a population-based cohort of veterans in Ontario. Data anonymisation and linkage including the addition of the unique encoded identified (ICES Key Number) and removal of the health card number was performed according to standard ICES protocol by the ICES Data Acquisition team, and identifying information was removed from the cohort prior to access by the authors.

VAC estimated that $31 \%$ of veterans-approximately 1050 individuals-transition from the military to civilian residence in Ontario each year. ${ }^{21}$ We do not know the true denominator of veterans living in Ontario during our study time frame; however, the number of veterans entering our cohort per year was similar to the expected number. We found a similar age, sex and length of service distribution in our cohort as reported by VAC. Our cohort has fewer younger veterans $(<25$ years old $)$ and a larger number of older veterans ( $\geq 50$ years) than expected; however, this is likely explained by our inclusion of RCMP veterans. ${ }^{18}$ We are unable to separately study CAF and RCMP veterans as the MOHLTC includes both under a single veteran status identifier variable. The large majority of our cohort are likely to be CAF veterans, rather than $\mathrm{RCMP}^{18}$ as $<200 \mathrm{RCMP}$ retire to Ontario per year (Drouin, personal communication). We therefore estimate that $\geq 80 \%$ of the cohort are CAF veterans.

We included male ex-serving members in this study if they registered for OHIP between January 1, 1990 and March 31, 2013. Female veterans were not included given the small percentage of the military who are female $(\sim 15 \%)^{22}$ and the rarity of suicide. We excluded individuals with OHIP coverage while still engaged in CAF or RCMP service, as indicated by OHIP billing record dates. Individuals were followed until death, OHIP coverage ended (eg, moved out of province) or until the end of the study period (December 31, 2015). The date of OHIP registration is a close approximation of the veterans' release date from the CAF or RCMP. ${ }^{18}$

Two civilian comparator groups were created by matching at a ratio of four civilians for one veteran: (1) on age (using birth year) and sex and (2) on age, sex and residential geography in the year following transition. Geographic region of residence was determined by Local Health Integration Networks (LHIN). Fourteen LHINs manage the financial planning and provision of healthcare in Ontario. Individuals were assigned to an LHIN based on their postal code.

Our previous work demonstrated temporal stability for the majority demographic details and that veterans are most likely to live within three regions of Ontario with close proximity to major bases and governmental 
departments. ${ }^{18}$ The two reference groups were chosen to be most comparable with other Canadian studies (age and sex alone ${ }^{15}$ ) and a study from Scotland that applied matching (age, sex and geography ${ }^{8}$ ). The OHIP registration date of the veteran was used as the index date for entry into the cohort for both the veteran and the matched civilian reference groups. Eligible civilian controls had to be alive at the study index date.

\section{Data sources}

The study linked multiple administrative datasets held at ICES. ICES is a prescribed entity under section 45 of Personal Health Information Protection Act and may collect data and conduct analyses to improve health and healthcare without individual consent. These datasets were linked at the individual level using unique encoded identifiers and analysed at ICES. The Registered Persons Database provided sociodemographic data on age, sex, region and rurality of residence in Ontario, as well as aggregate community-level median income. The OHIP database provided information on eligibility for provincial health services and was used to identify major physical and mental comorbidities. The Canadian Institute of Health Information Discharge Abstract Database (CIHI-DAD) provided information on hospitalisations and was also used to identify physical and mental health comorbidities. The National Ambulatory Care Reporting System (NACRS) provided diagnostic and service information on ED visits and was also used to identify physical and mental comorbidities. The Ontario Registrar General (ORG) database provided information on vital status and cause of death.

\section{Identifying deaths by suicide}

Death by suicide was the primary outcome of this study. We identified deaths using the ORG database which contains mandatory reported information from provincial death certificates. Deaths that occurred between January 1, 1990 and December 31, 2015 were captured using an established method that uses the underlying cause of death diagnoses related to suicide as per the International Classification of Disease (ninth edition) classification system (E950-E959) and a manner of death equal to suicide for deaths that occurred in 2013 and later. This method has 97\% sensitivity in identifying suicides from the ORG database. ${ }^{23}$ All other deaths were classified as being due to other causes.

\section{Covariates}

Covariates were selected from known predictors of suicide risk that were not along the causal pathway ${ }^{1}$ and measured in the first year of provincial health insurance eligibility: age (matching), sex (matching), geography (matching, sensitivity analysis only), physical illness, socioeconomic status and rurality of residence. Potential explanatory variables, such as mental illness, trauma or operational experiences (eg, deployment) were considered to occur along the causal pathway from military career to death by suicide and were not included as potential confounders. The presence of major comorbidities was classified using the John's Hopkins Aggregate Diagnosis Groups (ADGs). ${ }^{24}$ A score was used to reduce the number of individual variables in the model, rather than including the presence of particular physical health diagnoses specifically and to ensure only validated measures of such conditions were included. The ADGs are created using hospitalisation (CIHI-DAD), ED visits (NACRS) and physician billing (OHIP) data in Ontario in the 2 years following the index date. Information on health status while the veteran was still serving was not available, as this is captured in a separate, military healthcare system. By focusing on major ADGs, we hoped to decrease the likelihood of capturing new diagnoses that would not have existed the year previous to the transition from military to civilian life. Using information on the type, diagnoses and number of encounters, six ADGs are classified as 'major' and summed. ${ }^{24}$ Major ADGs included time-limited: major; time limited: major-primary infections; likely to recur: progressive; chronic medical: unstable; chronic specialty: unstable orthopaedics; injuries/adverse effects: major; and malignancy. The major psychosocial ADG was not included in the measure of comorbidity used to adjust for confounding in the comparison of suicide risk between veterans and non-veterans as differences in the occurrence of mental disorders could explain differences in suicide risk between veterans and civilians. Categories of 0,1 and 2+ major comorbidities were used in the analysis based on the distribution of data. Socioeconomic status was defined according to median community income quintile using census data linked to postal codes ( $1=$ lowest to 5 =highest). Rurality of residence was defined according to the Rurality Index of Ontario, in which municipalities are assigned a score $(0-100)$ based on total population, population density and travel times to healthcare centres. ${ }^{25}$ Individuals were assigned to a municipality using their postal code.

\section{Statistical analysis}

Descriptive statistics compared demographic characteristics between the veteran and civilian populations using $\chi^{2}$ tests for independence and $\mathrm{t}$-tests for categorical and continuous data, respectively. Crude death by suicide incidence rates, incidence rate ratios and 95\% confidence limits were calculated using the gamma distribution. Incidence rates were further stratified by age at release $(<30$, $30-39,40-49,50+)$, calendar year of release (1990-1999, 2000-2013), length of service $(<5,5-9,10-19,20+$ years $)$ and in 5-year time intervals following release $(0-5$, $5-10,10-15$ and $15-20$ years) to explore temporal and service-related patterns. Statistical comparisons of these strata were not completed given small sample sizes.

Multivariable competing risks analysis was completed using the Fine and Grey sub-distribution hazards regression to compare the risk of death by suicide and death by other causes between veterans and civilians. ${ }^{26}$ Individuals were censored at the end of the follow-up period if they 


\begin{tabular}{|c|c|c|c|}
\hline & Veterans $(n=20397)$ & Civilians ( $n=81559)$ & P value* \\
\hline Age at index (mean, SD) & $42.1(10.1)$ & $42.1(10.1)$ & 0.88 \\
\hline \# Major ADGs & & & $<0.001$ \\
\hline 0 & 12095 (59.3\%) & $45328(55.6 \%)$ & \\
\hline 1 & $5428(26.6 \%)$ & $22476(27.6 \%)$ & \\
\hline $2+$ & $2874(14.1 \%)$ & 13755 (16.9\%) & \\
\hline \# Minor ADGs & & & $<0.001$ \\
\hline 0 & $4248(20.8 \%)$ & $14896(18.3 \%)$ & \\
\hline 1 & $3129(15.3 \%)$ & $11112(13.6 \%)$ & \\
\hline 2 & $3213(15.8 \%)$ & $11870(14.6 \%)$ & \\
\hline $3+$ & $9807(48.1 \%)$ & $43681(53.6 \%)$ & \\
\hline Socioeconomic status & & & $<0.001$ \\
\hline Lowest & $2090(10.2 \%)$ & 16017 (19.6\%) & \\
\hline 2 & $3439(16.9 \%)$ & $15929(19.5 \%)$ & \\
\hline 3 & $4196(20.6 \%)$ & $15950(19.6 \%)$ & \\
\hline 4 & $5225(25.6 \%)$ & $16121(19.8 \%)$ & \\
\hline Highest & $4519(22.2 \%)$ & $16119(19.8 \%)$ & \\
\hline Missing & $928(4.5 \%)$ & $1423(1.7 \%)$ & \\
\hline Rurality & & & $<0.001$ \\
\hline Most urban & $11619(57.0 \%)$ & $58447(71.7 \%)$ & \\
\hline $10-30$ & $3812(18.7 \%)$ & $11300(13.9 \%)$ & \\
\hline $31-50$ & $2483(12.2 \%)$ & $7093(8.7 \%)$ & \\
\hline $51-70$ & $1381(6.8 \%)$ & $1803(2.2 \%)$ & \\
\hline Most rural & $197(1.0 \%)$ & $1222(1.5 \%)$ & \\
\hline Missing & 905 (4.4\%) & $1694(2.1 \%)$ & \\
\hline
\end{tabular}

${ }^{*} \mathrm{P}$ value from Kruskal-Wallis test (continuous) and $\mathrm{X}^{2}$ test (categorical).

Socioeconomic status=median community income quintiles and Rurality=Rurality Index of Ontario score, 0-100.

ADGs, John's Hopkins adjusted diagnostic groups.

had not experienced the event of interest for the analysis. Hazard ratios and $95 \%$ CIs were presented, further adjusted for baseline age (continuous), presence of major comorbidities $(0,1,2+)$, median community income (quintiles) and rurality of residence (Rurality Index of Ontario, 0-9 (most Urban), 10-30, 31-50, 51-70, 70+ (most rural)). Confounders were selected because their values differ between veterans and civilians and are associated with suicide risk. Individuals with complete data (97.7\% of the cohort) were included in the multivariable analyses. $\mathrm{P}$ values $<0.05$ were considered statistically significant; two-sided hypothesis tests were completed. All analyses were performed using SAS V.9.3 Copyright 2008 (Cary, North Carolina, USA).

\section{RESULTS}

In this analysis, 20397 veterans released to Ontario between 1990 and 2013 and 81559 age-matched non-veterans were included (figure 1). Together, they contributed over one million person-years of follow-up. Median follow-up from index was 10 years in veterans and 12 years in civilians. Almost half of veterans left the CAF or RCMP before 2001, and half released in 2001 or later. Length of service varied: $19.5 \%$ served $<5$ years, $16.4 \%$ served for $5-19$ years and $54.1 \%$ served $\geq 20$ years. Table 1 compares characteristics of the veteran and age-matched civilian cohorts. Veterans had significantly fewer major or minor physical and mental health conditions, were significantly less likely to live in communities with the lowest median income and were more likely to live in rural areas than the civilian cohort. Online supplementary table S1 compares demographic characteristics between the civilian and age, sex and geography matched cohorts.

Over the study period, $4.2 \%$ of the male veteran cohort died $(n=854)$ compared with $6.5 \%$ of the non-veteran cohort $(n=5294)$. Fifty-two per cent of deaths in male veterans occurred in those $<50$ years, compared with $43 \%$ of deaths in male civilians. The most common causes of death in both groups were cancer or diseases of the circulatory system. Overall, veterans had an $18 \%$ lower adjusted risk of dying from causes other than suicide, 
Table 2 Risk of death in male veterans residing in Ontario ( $n=20397$, median follow-up time 10 years), compared with age and sex matched civilians ( $n=81559$, median follow-up time 12 years)

\begin{tabular}{|c|c|c|c|c|c|}
\hline & \multirow[b]{2}{*}{ \# deaths } & \multirow{2}{*}{$\begin{array}{l}\text { Unadjusted HR } \\
(95 \% \mathrm{Cl})\end{array}$} & \multirow[b]{2}{*}{ P value* } & \multirow{2}{*}{$\begin{array}{l}\text { Adjusted+HR } \\
(95 \% \mathrm{Cl})\end{array}$} & \multirow[b]{2}{*}{ P value } \\
\hline & & & & & \\
\hline \multicolumn{6}{|c|}{ Death by suicide } \\
\hline Civilian & $189(0.23 \%)$ & 1.00 (reference) & 0.41 & 1.00 (reference) & 0.96 \\
\hline Veteran & $39(0.19 \%)$ & 0.86 (0.62 to 1.22$)$ & & 1.01 (0.71 to 1.43$)$ & \\
\hline \multicolumn{6}{|c|}{ Death from other causes } \\
\hline \multicolumn{6}{|c|}{ Veteran status } \\
\hline Civilian & $5105(6.3 \%)$ & 1.00 (reference) & $<0.001$ & 1.00 (reference) & $<0.001$ \\
\hline Veteran & $815(4.0 \%)$ & 0.68 (0.63 to 0.74$)$ & & 0.82 (0.76 to 0.89$)$ & \\
\hline
\end{tabular}

${ }^{*} \mathrm{P}$ value from the Fine and Grey modified Wald statistic.

$\dagger$ Adjusted for age, number of major physical and mental comorbidities $(0,1,2+)$, socioeconomic status (quintiles of median community income), rurality (rurality index of Ontario score, 0-9, 10-30, 31-50, 51-70, 70+).

compared with age-matched civilians (HR $0.82,95 \% \mathrm{CI}$ 0.76 to $0.89 ; \mathrm{p}<0.0001)$.

Death by suicide was rare in both cohorts: $4.6 \%$ of deaths in the veteran cohort $(\mathrm{n}=39)$ and $3.6 \%$ of deaths in the non-veteran cohort $(\mathrm{n}=189)$, respectively. The crude incidence rate of death by suicide in the veteran cohort was 16.1 per 100000 person-years (95\% CI 11.2 to 22.2 ) and 17.7 per 100000 person-years in the non-veteran cohort (95\% CI 15.2 to 20.6). Veterans and non-veterans had a similar risk of dying by suicide during the study period (table 2). The adjusted HR of death by suicide for veterans was 1.01 (95\% CI 0.71 to 1.43 ) compared with the age-matched non-veteran comparator group. The conclusions did not change when the civilian cohort was matched on both age and geography (online supplementary table $\mathrm{S} 2$ ).

Table 3 describes the incidence rates of suicide within the veteran cohort by age at release, length of service and calendar year of release. The patterns in crude incidence rates suggest that veterans aged $30-49$ years at the time of release and veterans who released after 2000 have a higher rate of death by suicide compared with other veterans. Veterans serving 5-9 years also appeared to have a higher rate of suicide, compared with other veterans. However, 95\% confidence limits are wide and overlapped for all estimates, owing to small absolute numbers within each category.

\section{DISCUSSION}

In our study, we found a similar risk of suicide among Canadian veterans compared with civilians. Patterns in suicide incidence rates suggest that veterans aged 30-49 years at the time of release, veterans released after 2000 and veterans who served 5-9 years have the highest risk within the veteran population; however, these were not statistically significant. Our finding of a similar risk of death by suicide in the veteran and civilian population is consistent with contemporary studies comparing ex-serving veteran populations and the general population in the UK, ${ }^{8112728}$ deployed veterans in Sweden ${ }^{13}$ and deployed veterans in the USA prior to $2009^{10}$.

Our study is inconsistent with suicide rates and comparisons with the general population reported by the Canadian ${ }^{15}$ and Australian governments, ${ }^{9}$ and the American peer-reviewed literature published since 2009 for

Table 3 Incidence rates of suicide in male veterans releasing between 1990 and 2013*

Rate of deaths by
suicide
per 100000 person-
years
$(n=20397)$

\begin{tabular}{lc}
\hline Age at release & $18.2(6.7-39.6)$ \\
$<30$ & $29.7(17.0-48.3)$ \\
$30-39$ & $18.7(10.7-30.3)$ \\
$40-49$ & $1.5(0.04-8.2)$ \\
$50+$ & \\
Calendar year of release & $13.9(8.5-21.4)$ \\
\hline 1990-1999 & $19.7(11.9-30.8)$ \\
\hline 2000-2013 & \\
\hline Length of service & $10.1(3.3-23.5)$ \\
\hline$<5$ years & $32.3(15.5-59.4)$ \\
\hline 5-9years & $23.5(10.7-44.5)$ \\
\hline 10-19years & $12.3(6.9-20.4)$ \\
\hline 20+ years & \\
\hline Time period following release & $21.3(13.5-32.0)$ \\
\hline 0-5years & $12.5(5.4-24.6)$ \\
\hline $6-10 y e a r s$ & $9.4(2.6-24.0)$ \\
\hline $11-15 y e a r s$ & \\
\hline
\end{tabular}

*Absolute numbers of suicides are not reported due to small cell sizes and privacy restrictions. 
veterans of the Afghanistan and Iraq conflicts. ${ }^{12}$ The VAC report concluded the age-adjusted suicide standardised mortality ratio in male veterans was 1.36 (95\% CI 1.30 to 1.44) times higher than in the general population when standardised to the 1991 Canadian population, and their reported crude rates were double those described in our study for both the veteran and civilian groups although we used the same data sources and definitions to identify death by suicide. ${ }^{15}$ Differences in study time frames, how the veteran populations were selected and who was included (eg, Canadian population versus Ontario alone) and differences in analytic approaches between our study and the VAC report may explain discordant findings. Differences between our study findings and the American and Australian experiences may be explained by variation in the underlying prevalence of post-traumatic stress disorder or suicide across military or general populations, or different combat and deployment experiences. ${ }^{29}$

In our study, age, length of service, era of release and the period following release appeared to modify the risk of death by suicide although our study was underpowered to identify significant differences. These results are situated within previouswork performed in other countries; however, they differ in detail. Whereas some authors have found a higher risk in young male serving and ex-serving military members, ${ }^{1115}$ as well as in older veterans, ${ }^{89}$ others identified significantly lower rates for older veterans compared with the general population. ${ }^{9}{ }^{15}$ Many studies highlight a higher risk in early service leavers: those who spend the least amount of time in the military, who may be medically released for mental health reasons and who may have less access to support. ${ }^{11}{ }^{15}$ Our study may not adequately capture those who serve the least amount of time if they are less likely to identify with the provincial health system as a veteran. In addition to military-specific differences and underlying suicide rates, these studies may reach different conclusions given their choice of referent population or due to statistical uncertainty.

Many factors may explain why suicide rates could be similar in the veteran and general populations, even if exposure to trauma and rates of mental disorders differ. The presence of positive psychological factors, such as resiliency, ${ }^{1}$ exposure to mental health training and suicide prevention efforts within the CAF and public safety occupations may mitigate the risk of suicide in the veteran population. Canadian serving members had higher odds of experiencing mental health-related stigma than the general population but were more likely to report seeking care. ${ }^{30}$ Many civilians in the general population do not have access to the same level of training, supports or resources that are available to serving and ex-serving personnel, and so, although exposure to trauma or stressful conditions may be higher and stigma may still exist, Canadian military members, veterans and their networks may be better prepared to deal with them.

The healthy worker effect, defined as the bias that exists when comparing an occupational cohort to a general population that includes those unable to work due to illness or disability, ${ }^{31}$ and possible misclassification of veteran status are two key limitations of this study. We addressed the healthy worker effect by adjusting for comorbidity which resulted in an attenuation of the observed difference between veterans and non-veterans, and the difference in respect of suicide remained non-significant. In addition, comorbidity may change over time resulting in residual confounding. However, we do not anticipate this would occur differently between the veteran and civilian population. Given these limitations, similar rates of death by suicide may be as meaningful as identifying an elevated risk. In addition, our means of identifying veterans in publicly funded health data is subject to limitations. A national registry of CAF or RCMP veterans does not exist. Our process of ascertainment requires self-identification of military or RCMP service history to the provincial ministry of health in order to access the provincial healthcare system. Therefore, while we are confident that those included in the study are truly military and RCMP veterans, as they must provide regulated documentation of their service history, we cannot be certain that all veterans disclose their status, in particular if they are not ill or do not require health services. However, instructions for switching to provincial health services are included and recommended to military personnel during the military-to-civilian transition. Our study observations may not be generalisable to young veterans who serve a short period of time prior to release as they may be less likely to be identified as a veteran on provincial health insurance.

We would have preferred to study risk within reservist and female veteran populations, or by service experience (eg, deployments, locations of service and combat experiences) or account for previous trauma experience or childhood adversity ${ }^{8}{ }^{15}$; however, we were unable to do so given data availability. We were also unable to study the risk of death by suicide separately for CAF and RCMP veterans, and this may overestimate or underestimate the effect in CAF personnel. A recent survey of mental health disorders among public safety personnel suggests many RCMP screen positive for trauma exposure and various mental health problems, ${ }^{32}$ although there are no data on suicide risk. In addition, RCMP personnel do not have the same access to mental health training and support as those in the CAF. In depth analyses of other-cause death, such as cancer or motor vehicle accidents, were outside the scope of our study. Future studies investigating differences in other-cause deaths are needed to create a more comprehensive picture of the impact of a military career on overall mortality.

\section{CONCLUSIONS}

Our study observed a similar suicide risk among veterans compared with a matched general population cohort. Our study's primary strength is its population-based design, including rigorous adjustment for confounding. Our observations are consistent with research in the UK 
and diverge from the only other Canadian study, as well as studies from the USA. Therefore, given the international focus on the issue of suicide among individuals serving or who have served in the military, this work raises a need to conduct further high-quality research on the topic of suicide in the military, including veteran populations. Similar rates of suicide-related mortality highlight the need and opportunity for earlier intervention. We recommend continued efforts around help-seeking for mental health conditions, increased focus on mental health and suicide prevention in the defence community and further suicide prevention strategy development.

Contributors AM, AK, MW and PK contributed to the conception and design of the work. AM, MW and PK contributed to the acquisition of data. AM and MW contributed to the analysis of the work. All authors (AM, AK, MW, HT, CH, NTF, PK) contributed to the interpretation of data, drafting and revising the manuscript critically for important intellectual content, approve the final version to be published and agree to be accountable for all aspects of the work.

Funding This study was funded by an unrestricted contribution from True Patriot Love, a philanthropic organisation dedicated to supporting Canadian veterans and their families. This study was partially supported by ICES, which is funded by an annual grant from the Ontario Ministry of Health and Long-Term Care (MOHLTC). Parts of this material are based on data and/or information compiled and provided by the Canadian Institute of Health Information (CIHI).

Competing interests The opinions, results and conclusions reported in this paper are those of the authors and are independent from the funding sources. No endorsement by ICES or the Ontario MOHLTC is intended or should be inferred. The analyses, conclusions, opinions and statements expressed in the material are those of the author(s), and not necessarily those of $\mathrm{ClHI}$.

Patient consent for publication Not required.

Ethics approval This study received ethics approval from the Queen's University Health Sciences Research Ethics Board.

Provenance and peer review Not commissioned; externally peer reviewed.

Data sharing statement The data set from this study is held securely in coded form at ICES. While data sharing agreements prohibit ICES from making the data set publicly available, access may be granted to those who meet prespecified criteria for confidential access (available at www.ices.on.ca/DAS). The full data set creation plan and underlying analytic code are available from the authors upon request, understanding that the programs may rely upon coding templates or macros that are unique to ICES.

Open access This is an open access article distributed in accordance with the Creative Commons Attribution Non Commercial (CC BY-NC 4.0) license, which permits others to distribute, remix, adapt, build upon this work non-commercially, and license their derivative works on different terms, provided the original work is properly cited, appropriate credit is given, any changes made indicated, and the use is non-commercial. See: http://creativecommons.org/licenses/by-nc/4.0/.

\section{REFERENCES}

1. Nock MK, Deming CA, Fullerton CS, et al. Suicide among soldiers: a review of psychosocial risk and protective factors. Psychiatry 2013;76:97-125.

2. Zamorski MA, Bennett RE, Rusu C, et al. Prevalence of past-year mental disorders in the Canadian Armed Forces, 2002-2013. Can J Psychiatry 2016;61(1 Suppl):26S-35.

3. Sareen J, Afifi TO, Taillieu T, et al. Trends in suicidal behaviour and use of mental health services in Canadian military and civilian populations. CMAJ 2016;188:E261-7.

4. Rusu C, Zamorski MA, Boulos D, et al. Prevalence comparison of past-year mental disorders and suicidal behaviours in the canadian armed forces and the canadian general population. Can J Psychiatry 2016;61(1 Suppl):46S-55.

5. Afifi TO, Taillieu T, Zamorski MA, et al. Association of Child Abuse Exposure With Suicidal Ideation, Suicide Plans, and Suicide
Attempts in Military Personnel and the General Population in Canada. JAMA Psychiatry 2016;73:229-38.

6. Sareen J, Afifi TO, Taillieu T, et al. Deployment-Related Traumatic Events and Suicidal Behaviours in a Nationally Representative Sample of Canadian Armed Forces Personnel. Can J Psychiatry 2017;62:795-804.

7. Shen YC, Cunha JM, Williams TV. Time-varying associations of suicide with deployments, mental health conditions, and stressful life events among current and former US military personnel: a retrospective multivariate analysis. Lancet Psychiatry 2016;3:1039-48.

8. Bergman BP, Mackay DF, Smith DJ, et al. Suicide in Scottish military veterans: a 30-year retrospective cohort study. Occup Med 2017;67:350-5.

9. Australian Institute of Health and Welfare. Incidence of suicide among serving and ex-serving Australian Defence Force personnel: Detailed analysis 2001-2015. Canberra, 2017.

10. Miller M, Barber $C$, Young $M$, et al. Veterans and suicide: a reexamination of the National Death Index-linked National Health Interview Survey. Am J Public Health 2012;102(Suppl 1):S154-9.

11. Kapur N, While D, Blatchley N, et al. Suicide after leaving the UK armed forces--a cohort study. PLOS Med 2009;6:e1000026.

12. Kang HK, Bullman TA, Smolenski DJ, et al. Suicide risk among 1.3 million veterans who were on active duty during the Iraq and Afghanistan wars. Ann Epidemiol 2015;25:96-100.

13. Pethrus CM, Johansson K, Neovius K, et al. Suicide and all-cause mortality in Swedish deployed military veterans: a population-based matched cohort study. BMJ Open 2017;7:e014034.

14. Thompson JM, VanTil LD, Zamorski MA, et al. Mental health of Canadian Armed Forces Veterans: review of population studies. J Mil Veteran Fam Health 2016;2:70-86.

15. Simkus K, VanTil L, Pedlar D. 2017 veteran suicide mortality study. Canada: Charlottetown PEI, 2017.

16. Mahar AL, Aiken A, Groome P, et al. A new resource to study the health of Veterans in Ontario. J Mil Veteran Fam Health 2015;1:3-5.

17. Aiken $A B$, Mahar AL, Kurdyak $P$, et al. A descriptive analysis of medical health services utilization of Veterans living in Ontario: a retrospective cohort study using administrative healthcare data. BMC Health Serv Res 2016;16:351.

18. Mahar AL, Aiken AB, Kurdyak $P$, et al. Description of a longitudinal cohort to study the health of Canadian Veterans living in Ontario. $J$ Mil Veteran Fam Health 2016;2:33-42.

19. Mahar AL, Aiken AB, Cramm H, et al. Mental health services use trends in canadian veterans: a population-based retrospective cohort study in Ontario. Can J Psychiatry 2018;63.

20. von Elm E, Altman DG, Egger M, et al. The Strengthening the Reporting of Observational Studies in Epidemiology (STROBE) statement: guidelines for reporting observational studies. Lancet 2007;370:1453-7.

21. MacLean MB, Poirier A, O'Connor T. Province of residence at release and post-release- Data from the income study. Canada VA: Charlottetown, Prince Edward Island: Veterans Affairs Canada, 2011.

22. Manser L. Profile of military families in Canada: 2017 regular force demographics. Ottawa, ON, 2018.

23. Gatov E, Kurdyak P, Sinyor M, et al. Comparison of vital statistics definitions of suicide against a coroner reference standard: a population-based linkage study. Can J Psychiatry 2018;63:152-60.

24. Johns Hopkins University. The Johns Hopkins ACG® System Version 11.0 Technical Reference Guide, 2014.

25. Kralj B. Measuring Rurality-RIO2008 BASIC: methodology and results. Toronto: Ontario Medical Association, 2008.

26. Lau B, Cole SR, Gange SJ. Competing risk regression models for epidemiologic data. Am J Epidemiol 2009;170:244-56.

27. Ministry of Defence. A study of deaths among UK Armed Forces personnel deployed to the 1982 Falklands campaign: 1982-2012. United Kingdom, 2013.

28. Ministry of Defence. 1990/1991 Gulf Conflict UK Gulf Veterans Mortality Data: Causes of Death. United Kingdom, 2016.

29. Goodwin L, Wessely S, Fear NT. The future of "Big Data" in suicide behaviors research: can we compare the experiences of the U.S. and U.K. Armed Forces? Psychiatry 2015;78:25-8.

30. Weeks M, Zamorski MA, Rusu C, et al. Mental illness-related stigma in canadian military and civilian populations: a comparison using population health survey data. Psychiatr Serv 2017;68:710-6.

31. Porta M, A dictionary of epidemiology. 6th edn, 2014.

32. Carleton RN, Afifi TO, Turner S, et al. Mental disorder symptoms among public safety personnel in Canada. Can J Psychiatry 2018;63:54-64. 